\title{
Acil servise başvuran migren hastalarının özürlülük, anksiyete ve depresyon oranlarının belirlenmesi
}

\section{Determination of disability, anxiety and depression rates of migraine patients admitted to emergency department}

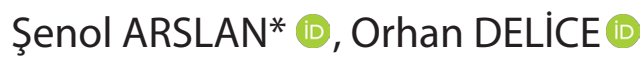

Sağlık Bakanlığı Üniversitesi Erzurum Bölge Eğitim ve Araştırma Hastanesi, Acil Servis, Erzurum/ Türkiye.

\section{Öz}

Amaç: Çalışmamızın amacını acil servise başvuran migren hastaları ile sağlıkı kontrol grubu arasındaki anksiyete, depresyon ve özürlülük oranlarının belirti düzeylerinin karşılaştıııması ve bu düzeylerin hastalık süresi ve atak sıklığı ile ilişkisinin incelenmesi olarak belirledik.

Gereç ve Yöntemler: Migren tipi baş ağrısı olan hastalara Hastane anksiyete ve depresyon ölçeği (HAD) ve Migren Özürlülük Değerlendirme Ölçeği (MIDAS) kullanılarak hazırlanmış olan form dolduruldu. Kontrol grubuna ise Hastane anksiyete ve depresyon ölçeği dolduruldu. Daha sonrasında bu hastaların ve kontrol grubunun anksiyete, depresyon ve özürlülük oranları tespit edilip demografik verilerle beraber karşılaştırmalar yapıldı.

Bulgular: Çalışmamızda cinsiyet ve atak sıklığı ile midas skorları arasında anlamlı pozitif bir ilişki bulunmuştur. Deney ve kontrol grubunda, anksiyete ile depresyon açısından anlamlı bir farklıık olup olmadığına bakılmış olup, analiz sonucunda, 0.00 anlamlılık seviyesinde, bağımsız değişkenin hem anksiyetehem de depresyon için etkisi istatistiksel olarak anlamlı bulunmuştur. Deney grubunda anksiyete, depresyon ve Midas skorları kendi aralarında değerlendirildi. Analiz sonucunda, Midas ile anksiyete ve depresyon arasında pozitif bir ilişki bulunmuştur. Deney ve kontrol grubunda depresyon ve anksiyete arasındaki ilişkiye bakıldı. Analiz sonucunda; Her iki grupta da depresyon ve anksiyete arasında 0.00 düzeyinde pozitifi anlamlı bir iliş̧i bulunmuştur.

Sonuç: Migreni olan hastaların depresyon ve anksiyetelerini kontrol edersek, bu hastaların hayat standartlarını artııı migrenden kaynaklanan özürlülük oranlarını azaltacağımızı düşünüyoruz. Bu nedenle migren tanısı olan hastaların psikiyatrik komorbiditeler açııından mutlaka sorgulanması ve bu hastalar için multidisipliner bir yaklaşım modeli sergilenmesi gerektiğini düşünmekteyiz.

Anahtar kelimeler: migren; anksiyete; depresyon

Sorumlu Yazar*: Şenol Arslan, Sağlık Bakanlığı Üniversitesi Erzurum Bölge Eğitim ve Araştırma Hastanesi, Acil Servis, Erzurum/Türkiye E-mail: drsenolarslan@gmail.com 


\begin{abstract}
Aim: The aim of our study was to compare the symptom levels of anxiety, depression and disability rates between migraine patients and the healthy control group presenting to the emergency department, and to investigate the relationship between these levels and duration of disease.
\end{abstract}

Material and Methods: Patients with migraine headache were filled in the form prepared using the Hospital Anxiety and Depression Scale (HAD) and the Migraine Disability Assessment Scale (MIDAS). The hospital anxiety and depression scale was filled in the control group. Then, anxiety, depression and disability rates of these patients and control group were determined and comparisons were made with demographic data.

Results: In our study, a significant positive relationship was found between sex and attack frequency and midas scores. In the experimental and control groups, a positive significant correlation was found between the levels of anxiety and depression at the level of 0.00 . In the experimental group, anxiety, depression and Midas scores were evaluated. As a result of the analysis, a positive relationship was found between Midas and anxiety and depression. The relationship between depression and anxiety was examined in the experimental and control groups. As a result of the analysis; In both groups, a positive correlation was found between depression and anxiety at a level of 0.00 .

Conclusion: If we control the depression and anxiety of patients with migraine, we believe that we will increase the living standards of these patients and decrease the disability rates caused by migraine. Therefore, we think that patients with migraine should be questioned in terms of psychiatric comorbidities and a multidisciplinary approach model should be exhibited for these patients.

Keywords: migraine; anxiety; depression

\section{Giriş}

Baş ağrısı toplumda sık görülen önemli bir sağlık sorunudur. Primer baş ağrıları içinden sık görülenleri gerilim tipi baş ağrısı ve migrendir [1,2]. Migren genetik, hormonal, çevresel, diyet, uyku ve her bireyde farklı psikolojik durumların eşlik ettiği çok faktörlü biyodavranışsal bir hastalık olarak bilinir [3]. Toplumlarda \%12-18 görülme sıklığı olan migren, özürlülük ve performans kaybına sebep olan ciddi bir halk sağlığı sorunudur $[1,2]$.Migren sıklıkla kardiyovasküler, nörolojik ve psikiyatrik bozukluklarile beraber görülebilmektedir [4]. Normal popülasyona göre migren hastalarındaanksiyete ve depresyon sık görülen psikiyatrik rahatsızlıklardır. Bu duygu-durum bozukluklarıda migren hastalarının tedavisini güçleştirip hayat kalitesini olumsuz anlamda etkiler [5,6]. Depresyon ve anksiyete gibi durumlar migren hastalarında atak sıklığını artırabilir ve hastalığın kronikleşmesine neden olabilir $[7,8]$. Auralı migren ile aurasız migrenlileri karşılaştıran çalışmalar, psikiyatrik bozuklukların auralı migreni olan hastalarda daha sık olduğunu göstermiştir [9]. Migren ile depresyon arasındaki bu ilişki iki taraflıdır. Yani depresyon hastalarında migrenin ortaya çıkma riski; depresyonu olmayan kişilere göre üç kat daha fazladır. Benzer şekilde migreni olan hastalarda da depresyonun ortaya çıkma riski, migreni olmayanlardan üç kat daha fazladır [10].

Migren hastalarında ortaya çıkan özürlülük, anksiyete ve depresyon gibi durumlar hastalar tarafından ifade edilemeyebilir, bazen de klinisyenler tarafından sorgulanmaz. Bundan dolayı migrenin tedavisi eksik ve yetersiz kalmaktadır. Tedavideki bu eksikliğin en önemli nedeni olarak; çoğu migren hastasının tanı aldıktan sonra rutin kontrollerini yaptırmayıp sadece migren atakları sırasında analjezi için acil servise başvurmaları, gösterilebilir. Sonuç olarak migren birçok açıdan ele alınıp tedavi edilmelidir.Çalışmamızın amacını acil servise başvuran migren hastalarında özürlülük, anksiyete ve depresyon belirti düzeylerinin kontrol grubu ve migren alt grupları (auralı ve aurasız) ile karşılaştırılması ve bu düzeylerin migren atak sıklığı ve hastalık süresi ile olan ilişkisinin araştırılması olarak belirledik. Böylelikle migren hastalarına multidisipliner bir yaklaşım modeli sergilenerek yaşam kalitesinde artış, özürlülük oranlarında azalma olacağını düşünmekteyiz.

\section{Yöntemler}

Bu araştırma Erzurum Bölge Eğitim Araştırma Hastanesi Acil Tıp kliniğinde migren hastalarında kesitsel tipte tanımlayıcı bir araştırma olarak yapılmıştır. Yerel Etik Kurul onayı (Karar No 2019/02-25) alınmıştır ve 1964 Helsinki Bildirgesi'nde ve daha sonraki değişikliklerinde belirtilen etik standartlara uygun olarak gerçekleştirilmiştir. Çalışmadan önce tüm alt gruplardan bilgilendirilmiş onam alındı.Çalışmaya kayıtlı tüm hastalar Şubat ile Mayıs 2019 arasında Acil Servisimize ardışık olarak başvurdu. Çalışmaya migren tanısı olan 100 hasta, cinsiyet ve yaşa göre hasta olgularla eşleştirilen 100 sağlıklı 
gönüllü aldık.Çalışmaya Uluslararası Baş Ağrısı Topluluğu'nun tanı kriterlerine göre daha önceden bir nörolog tarafından migren tanısı konulmuş yetişkin (18 yaş üstü) hastalar ile kontrol grubu olarak sağlıklı gönüllüler dahil edildi. Sekonder baş ağrısı olan vakalar (Hipertansiyonu, kafa travması vb... ), gebe ve emziren kadınlar ile 18 yaş altındaki hastalar çalışma dışı bırakıldı. Ayrıca daha önce bir serebral kanama, serebrovasküler olay, geçici iskemik atak, hemorajik enfarktüs, beyin travması, enflamatuar veya enfeksiyöz hastalık, tümör, hematolojik bozukluk, otoimmün bozukluk, hepatik veya böbrek hastalığı, hiper veya hipotiroidi rahatsızlıkları ve koopere olmayan hastalar çalışma dışı bırakıldı.Araştırmaya dâhil edilen hastalar için oluşturulan formda demografik ve klinik verileri şunları içermiştir: yaş, cinsiyet, eğitim seviyesi, özgeçmiş (anksiyete, depresyon öyküsü), ateş, nabız, tansiyon arteriyel, baş ağrısı için ilaç kullanımı, baş ağrısının şiddeti (Ulusal ağrı skalası ölçeği kullanılarak ölçüldü), migren için profilaksi alıp almadığı, atak sıklığı, hastalığın süresi ve baş ağrısının tipi (auralı yada aurasız migren ). Ayrıca bu formda özürlülük oranı ile anksiyete ve depresyonu ölçmek için ölçeklere yer verildi. Hastalardan anket şeklinde hazırlanan ölçekleri doldurması istenildi. Hastalar bu ölçekleri ağrısız dönemlerinde doldurdu. Ölçek olarak; Hastane anksiyete ve depresyon ölçeği (HADÖ) ve Migren Özürlülük Değerlendirme Ölçeği (MIDAS) kullanıldı.

\section{Hastane anksiyete ve depresyon ölçeği:}

1983 yılında Zigmond ve arkadaşları toplum ve hastane örnekleminde kolayca uygulanabilen, tıbbi bir hastalığı olan topluluklardaki pisikiyatrik bozuklukları tespit etmek için hastane anksiyete ve depresyon ölçeğini geliştirmişlerdir. Hastane anksiyete ve depresyon ölçeğinin ondört maddesi olup hastalar tarafından kolaylıkla doldurulabilir. Depresyon ve anksiyeteyi ölçen iki alt ölçek şeklinde tasarlanmıştır. Depresyon alt ölçeği yedi maddeden oluşmakla beraber 0-21 arasında skorlanmaktadır, 0-7= Normal, 8-10= Hafif, 11 ve üstü anormalbir duygudurum bozukluğuna işaret etmektedir [11].

\section{Migren Özürlülük Değerlendirme Ölçeği (MIDAS):}

Migren Özürlülük Değerlendirme Ölçeği okul, ev ve işyeri ile alakalı beş sorudan oluşur. MIDAS skoru ağrıdan dolayı çalışılamayan günler ve $\% 50$ performans kaybının olduğu günlerin sorgulanması neticesinde alınan puanlar ile elde edilir. MIDAS ölçeği hastaları dört gruba ayırır. Grup 1: 0-5 gün kayıp (özürlülük çok az yada hiç yok),Grup II: 6-10 gün kayıp (Hafif düzeyde Özürlülük), Grup III: 11-20 gün kayıp (Orta düzeyde Özürlülük) ve Grup IV : 21+ gün kayıp(Ciddi düzeyde Özürlülük) demekti [12].

\section{Bulgular}

Çalışmaya, migren tanısı olan 100 hasta ve 100 kontrol olmak üzere toplam 200 denek alındı. Hasta grubunun cinsiyet, yaş, proflaksi alıp almadığı, ağrı skalası, atak sıklığı, hastalığın süresi, auralı yada aurasız olup olmamasına göre dağılımları ile bu değişkenlerin anksiyete, depresyon ve MIDAS skorlarıyla ilişkisi incelendi (Tablo 1).

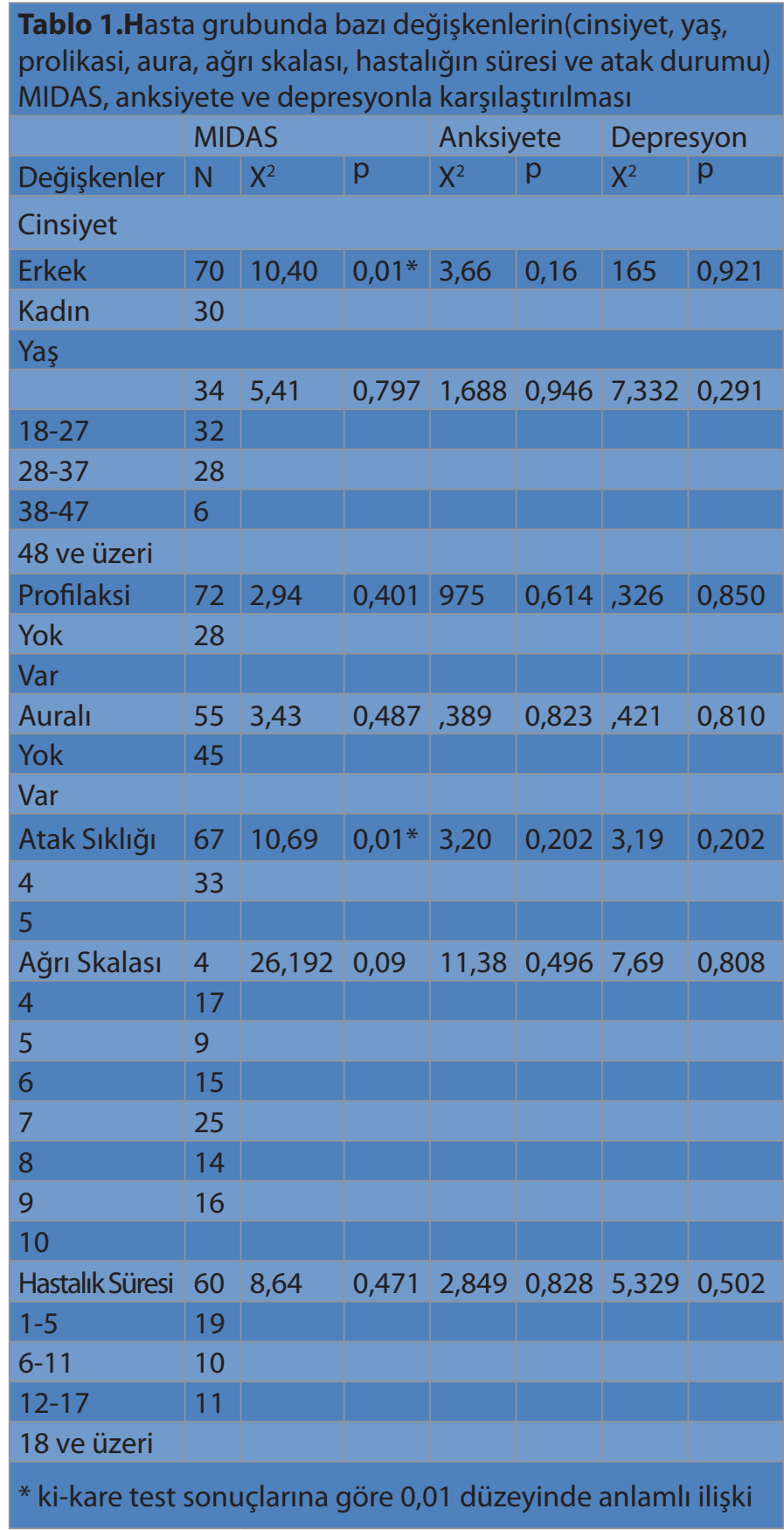

Verilerin analizinden önce, yaş ve hastalık süresi uygun şekilde gruplandırılmıştır. Analizler sonucunda tablo 1 de görülebileceği gibi, sadece cinsiyet ve atak sıklığı ile MIDAS skorları arasında anlamlı bir ilişki bulunmuştur. Kikare testi sonuçlarına göre cinsiyet ile MIDAS arasında ilişki istatistiksel olarak anlamlıdır $(x 2(3)=10,404, p=0,01)$. Oluşan 
bu anlamlı ilişkinin MIDAS değerlerinin hangi grubunda oluştuğunu belirlemek için Post-hoc analizi yapılmış ve $p$ değerleri oluşturulmuştur. Buna göre, "Hiç kayıp yok ya da çok az" $(p=0,01)$ ve "Ciddi kayıp" $(p=0,03)$ gruplarının bu farkı oluşturduğu görülmüştür.

Benzer şekilde atak sıklığı ile MIDAS arasındaki ilişki istatstiksel olarak anlamlıdır $(x 2(3)=10,694, p=0,01)$. Sonuçlar MIDAS grupları açısından incelendiğinde ise sadece "Ciddi kayıp" $(p=0,02)$ grubunda bu farkın oluştuğu belirlenmiştir.

Çalışmamızda deney ve kontrol grubunda, anksiyete ile depresyon açısından anlamlı bir farklılık olup olmadığına bakıldı (Tablo 2).

\begin{tabular}{|c|c|c|c|c|c|c|c|}
\hline \multirow[b]{2}{*}{$\begin{array}{l}\text { Bağımlı } \\
\text { Değişkenler }\end{array}$} & \multicolumn{3}{|c|}{ Hasta } & \multicolumn{4}{|c|}{ Kontrol } \\
\hline & $\mathrm{N}$ & $x$ & SS & $\mathrm{N}$ & $X$ & SS & $p$ \\
\hline Anksiyete & 100 & 10,63 & 3,42 & 100 & 7,12 & 3,99 & $0,000^{*}$ \\
\hline Depresyon & 100 & 10,14 & 3,91 & 100 & 6,39 & 3,38 & $0,000^{*}$ \\
\hline \multicolumn{8}{|l|}{ Anksiyete } \\
\hline Normal & 20 & & & 63 & & & $0,000^{* *}$ \\
\hline Sınırda & 26 & & & 19 & & & $0,487^{* *}$ \\
\hline Anormal & 54 & & & 18 & & & $0,000^{* *}$ \\
\hline \multicolumn{8}{|l|}{ Depresyon } \\
\hline Normal & 26 & & & & 64 & & $0,000^{* *}$ \\
\hline Sınırda & 23 & & & & 29 & & $0,607^{* *}$ \\
\hline Anormal & 51 & & & & 7 & & $0,000^{* *}$ \\
\hline \multicolumn{8}{|c|}{$\begin{array}{l}\text { * Tek yönlü ANOVA test sonuçlarına göre } 0.01 \text { düzeyinin altında } \\
\text { anlamlı ilişki }\end{array}$} \\
\hline \multicolumn{8}{|c|}{ ** ki-kare test sonucuna bağlı post-hoc analizi } \\
\hline
\end{tabular}

Depresyon ve anksiyete üzerine grup etkisini araştırmak için tek yönlü ANOVA uygulanmış ve analizlerden önce test için gerekli bütün varsayımlar kontrol edilmiştir. Analiz sonucunda, 0,00 anlamlılık seviyesinde, bağımsız değişkenin hem anksiyete $[F(1,198)=50,155, p=0,000]$ hem de depresyon $[F(1,198)$ $=60,926, p=0,000]$ için etkisi istatistiksel olarak anlamlı bulunmuştur. Bu anlamlı farkın anksiyete ve depresyonun hangi grupları arasında olduğunu belirlemek için ki-kare test kullanılmıştır. Ki-kare sonuçlarına göre, anksiyete ile hasta ve kontrol grubu arasındaki ilişki, normal $(p=0,00)$ ve anormal $(p=0,00)$ grubunda istatistiksel olarak anlamlı bulunmuştur. Diğer taraftan, sınırda grubunda yer alanlar için ilişki anlamlı bulunamamıştır $(p=0,487)$. Benzer bir durum depresyon içinde gözlenmiştir. Buna göre, deney ve kontrol grubu ile depresyon skorları arasındaki fark sadece normal ve anormal grubunda istatistiksel olarak anlamlı bulunmuştur. Yine sınırda grubunda yer alanlar için fark/ilişki istatistiksel olarak anlamlı değildir.
Deney grubunda anksiyete, depresyon ve MIDAS skorları kendi aralarında değerlendirildi (Tablo 3 ).

\begin{tabular}{|c|c|c|c|c|}
\hline \multicolumn{3}{|l|}{ Değişkenler } & \multicolumn{2}{|c|}{ Korelasyonlar } \\
\hline & $X$ & SS & 1. & 2. \\
\hline 1. MIDAS & 31,46 & 22,03 & & \\
\hline 2. Anksiyete & 10,63 & 3,424 & $196^{*}$ & \\
\hline 3. Depresyon & 10,14 & 3,913 & $236^{*}$ & $446^{* *}$ \\
\hline
\end{tabular}

MIDAS skorlarının depresyon ve anksiyete ile ilişkisini belirlemek için Pearson's r korelasyon analizi yapılmıştır. Analiz sonucunda, MIDAS ve anksiyete arasında 0.05 anlamlılık düzeyinde pozitif ilişki bulunurken[ $r=, 196, n=100, p=0,04]$, midas ve depresyon arasında ki anlamlılık düzeyin 0,01 olarak tesbit edilmiştir[ $r=, 236, n=100, p=0,01]$. Buna göre, MIDAS skorları yükseldikçe, hem anksiyete hem depresyon skorlarının yükseldiği gözlemlenmiştir.

Deney grubunda depresyon ve anksiyete arasında yine 0,00 düzeyinde pozitifi anlamlı bir ilişki bulunmuştur $[r=446, n$ $=100, p=0,00]$. Benzer şekilde kontrol grubunda da anksiyete ve depresyon arasında ki ilişkiye bakılmış ve 0,00 anlamlılık düzeyinde pozitif bir ilişki bulunmuştur. $[r=, 578, n=100, p=0,00]$.

\section{Tartışma}

Migren hastalarında özürlülük şiddetini belirlemek, hastaların tedavi planlamasında ve tedaviye verdikleri yanıtın gözlenmesi aşamasında önemlidir. $\mathrm{Bu}$ nedenle ülkemizde migren hastalarında tedavi yöntemini ve hastalığın şiddetini belirlemede güvenilir bir ölçek olduğu yapılan çalışmalar ile bilinen MIDAS skoru kullanılmaktadır. MIDAS son 3 ay içindeki migren ile ilişkili özürlülüğü belirler [13].Çalışmamızda migren hastaları cinsiyet, yaş, profilaksi alıp almadığı, ağrı skalası, atak sıklığı, hastalığın süresi, auralı yada aurasız olup olmamasına göre dağılımları ile bu değişkenlerin anksiyete, depresyon ve midas skorlarıyla ilişkisi incelenmiş olup sonuçta erkek cinsiyet ile atak sıklığının Midas skoruyla pozitif anlamda ilişkili olduğu gözlendi.

Bazı çalışmalarda cinsiyet ile MIDAS arasında istatistiksel olarak anlamlı fark saptanmazken bizim çalışmamızda erkek cinsiyet ile MIDAS skorları ilişkiliydi. Birçok çalışma bizim çalışmamıza benzer şekilde atak sıklığı ile MIDAS arasında pozitif ilişki olduğunu göstermiştir. Buna göre atak sıklığı arttıkça özürlülük oranı artmaktaydı. Buda bize atak sıklığının hastalığının şiddetini belirleyen önemli bir etken olduğunu gösteriyor [14,15].

Çalışmamızda birçok migren hastasının artmış atak sıklığına rağmen her hangi bir profilaktik ilaç kullanmadığı gözlemlendi. 
Acil servise sık sık atak ile başvuran migren hastaları, sosyal ve ekonomik anlamda ciddi bir halk sağlığı sorunudur. Bu veriler ışığında hastalarda iş gücü kaybına, artmış tedavi masraflarına ve sosyal aktivitelerinde azalmaya neden olan migren ile ilişkili özürlülüğün başarılı bir tedaviyle düzletilebileceğini düşünüyoruz.

Atak sıklığı ve auralı migrenin, depresyonla pozitif bir ilişkisinin olduğunu gösteren çalışmalar vardır [9,16,]. Ancak biz çalışmamızda böyle bir ilişki saptamadık.

Migren hastalarında major depresif bulgular, anksiyete ve panik bozukluk oldukça sıktır [17,18,19]. Migren hastalarında depresyon düzeylerinin kontrol grubuna göre 2,5 kat arttığını gösteren çalışmalar vardır[20]. Ayrıca depresyon ve migren ile alakalı yapılan bir meta analiz çalışması, depresyonun migren hastalarında \% 8,6 ile \% 47,9 gibi oldukça değişken oranda olduğunu göstermiştir [6].Bir başka çalışmada ise migren ve depresyonun birbirlerinin sıklığını arttırdığı gösterilmiştir [21]. Bizim çalışmamızda da literatürle uyumlu olarak depresyon düzeyleri kontrol grubuna göre anlamlı düzeyde yüksek bunmuştur. (Tablo 2)

Kronikbirağrıyasebepolanmigrendepresyongibiduygudurum bozukluklarıyla direkt alakalı olmayabilir. Bazı çalışmalarda diğer baş ağrısı nedenleri ile migren arasında pisikiyatrik hastalıklar açısından anlamlı farklılık olmadığı gösterilmiştir $[22,23]$. Ağrı ve depresyon benzer nörotransmiterleri ve biyolojik yolakları kullanır [24]. Migrende kronik ağrıya neden olan bir durum olduğundan,migren ile depresyon arasında bu nedenden dolayı direk ilişkili olmasada indirek bir ilşki olduğu dadüşünülebilir.Ayrıca trisiklik antidepresanların migrenin önlenmesindeki etkinliği, depresyon ve migren için ortak bir nedensel mekanizma olduğunu ortaya koymaktadır [19].

Migren hastalarında anksiyete bozklukları genel popülasyona göre 2 ila 5 kat fazla görülür. Bu durumun kronik migren hastalarında daha yaygın olduğu [25] ve migren ile anksiyete arasında çift yönlü bir ilişki olduğunu gösteren çalışmalar vardır. Yani anksiyete hastalarında migren görülme sıklığının, migren hastalarında anksiyete görülme sıklığıyla benzer olduğunu gösteren çalışmalar[26]. Bu ilişki de çeşitli hipotezler ile aydınlatılmaya çalışılmıştır[27]. Literatürle uyumlu olarak bizim çalışmamızda da anksiyete düzeyleri kontrol grubuna göre anlamlı düzeyde yüksek bunmuştur. (Tablo 2 )

Yapılan bazı çalışmalarda[18] hastalık süresi ile anksiyete ve depresyon arasında pozitif ilişki saptanmıştır ancak, bizim çalışmamızda anlamlı bir ilişki saptanmadı. Çalışmamızda anksiyete, depresyon ve MIDAS skorlarının kendi arsındaki ilişkisine bakılmış olup sonuçlar Tablo 3 de gösterilmiştir. Analizler neticesinde MIDAS skoru yükseldikçe anksiyete ve depresyon oranlarının yükseldiği gözlendi.
Literatüre bakıldığında migren hastalarında anksiyete ve depresyon birlikteliği sık olup, bu ikili arasında pozitif anlamlı bir ilişki olduğu gözlenmiştir[25]. Benzer şekilde bizde çalışmamızda anksiyete ve depresyon arasında da pozitif anlamlı ilişki bulduk.

\section{Sonuç}

Depresyon ve anksiyete migrende sık görülen duygu durum bozuklukları olup migren hastalarının etkili tedavilerini zorlaştırmaktadır. Çalışmamızda depresyon ve anksiyete düzeylerinin migren hastalarında kontrol grubuna göre anlamlı derecede yüksek olduğunu tesbit ettik. Ayrıca hasta grubunda bakılan MIDAS, anksiyete ve depresyon skorları birbiriyle ilişkiliydi. Migren hastalarında anksiyete ve depresyonu tanıyıp tedavi etmek çok önemlidir. Çünkü anksiyete ve depresyon migrenin kronikleşmesinin nedenlerindendir(28). Migren mortaliteye neden olmadığından dolayı, halk sağlığı açısından ehemmiyetini gözden kaçırıyor olabiliriz. Oysaki çalışmamızda da görüldüğü gibi migren çalışmayı ve sosyal aktiviteleri ciddi anlamda etkilemektedir.Migreni olan hastaların depresyon ve anksiyetelerini kontrol edersek, bu hastaların hayat standartlarını artırıp migrenden kaynaklanan özürlülük oranlarını azaltacağımızı düşünüyoruz. Böylelikle migrenin daha etkin bir şekilde tedavi ediliceği kanaatindeyiz. $\mathrm{Bu}$ nedenle migren tanısı olan hastaların psikiyatrik komorbiditeler açısından mutlaka sorgulanması ve bu hastalar için multidisipliner bir yaklaşım modeli sergilenmesi gerektiğini düşünmekteyiz.Sonuç olarak hasta ve biz hekimlere yönelik, migrenin etkili tedavisinin önemini hatırlamak ve öğrenmek için küresel ölçekte eğitimler yapılabilir.Böylelikle migrene bağlı özürlülükleri azaltıp etkili tedavilerini sağlayabiliriz.

\section{Çıkar çatışması / finansal destek beyanı}

Bu yazıdaki hiçbir yazarın herhangi bir çıkar çatışması yoktur. Yazının herhangi bir finansal desteği yoktur.

\section{Kaynaklar}

1. Adoukonou T, Houinato D, Kankouan J et al. Migraine among university students in Cotonou (Benin). Headache 2009; 49: 887-93.

2. Yalug I, Selekler M, Erdogan A et al. Correlations between alexithymia and pain severity, depression, and anxiety among patients with chronic and episodic migraine. Psychiatry Clin Neurosci 2010; 64: 231-38.

3. Goadsby PJ. Decade in review-migraine: incredible progress for an era of better migraine care. Nat Rev Neurol 2015; 11: 621.

4. Radat F, Swendsen J. Psychiatric comorbidity in migraine: a review. Cephalalgia 2005; 25: 165-78.

5. Senaratne R, Van Ameringen M, Mancini C, Patterson B, Bennett 
M. The prevalence of migraine headaches in an anxiety disorders clinic sample. CNS Neurosci Ther 2010; 16: 76-82.

6. Antonaci F, Nappi G, Galli F, Manzoni GC, Calabresi P, Costa A. Migraine and psychiatric comorbidity: a review of clinical findings. J Headache Pain 2011; 12: 115.

7. Oh K, Cho SJ, Chung YK, Kim JM, Chu MK. Combination of anxiety and depression is associated with an increased headache frequency in migraineurs: a population-based study. BMC Neurol 2014; 14: 238.

8. Buse DC, Silberstein SD, Manack AN, Papapetropoulos S, Lipton RB. Psychiatric comorbidities of episodic and chronic migraine. J Neurol 2013; 260: 1960-69.

9. Samaan Z, Farmer A, Craddock $\mathrm{N}$ et al. Migraine in recurrent depression: case-control study. Br J Psychiatry 2009; 194: 350-54.

10. Torelli P, D'Amico D. An updated review of migraine and comorbid psychiatric disorders. Neurol Sci 2004; 25: 234-35.

11. Zigmond AS, Snaith RP. The hospital anxiety and depression scale. Acta Psychiatr Scand 1983; 67: 361-70.

12. Ertaş M, Siva A, Dalkara, et al. Validity and reliability of the Turkish Migraine Disability Assessment (MIDAS) questionnaire. Headache 2004; 44: 786-93.

13. Boylu E, Adıgzel T, Zden T. Migrenli Olgularda Dizabilitenin Midas Ölçeği ile Değerlendirilmesi. Duzce Medical Journal 2012; 14: 10-13.

14. D'Amico D, Genco S, Perini F. Workplace disability in migraine: an Italian experience. Neurol Sci 2004; 25: 251-52.

15. Stewart WF, Lipton RB, Kolodner K. Migraine disability assessment (MIDAS) score: relation to headache frequency, pain intensity, and headache symptoms. Headache 2003; 43: 258-65.

16. Breslau N, Schultz LR, Stewart WF, Lipton RB, Lucia VC, Welch KMA. Headache and major depression: is the association specific to migraine? Neurology 2000; 54: 308.

17. Senaratne $R$, Van Ameringen $M$, Mancini $C$, Patterson B, Bennett $M$. The prevalence of migraine headaches in an anxiety disorders clinic sample. CNS Neurosci Ther 2010; 16: 76-82.
18. Hung $\mathrm{Cl}$, Liu CY, Cheng YT, Wang SJ. Migraine: a missing link between somatic symptoms and major depressive disorder. J Affect Disord 2009; 117: 108-15.

19. Yaşar H, Balıbey H, Alay S, Tekeli H, Türker T, Bayar N. Migren hastalarında anksiyete, depresyon ve obsesif-kompulsif belirti düzeyleri. Journal of Mood Disorders 2013; 3: 156-61.

20. Minen MT, De Dhaem OB, Van Diest AK et al. Migraine and its psychiatric comorbidities. J Neurol Neurosurg Psychiatry 2016; 87: 741-49.

21. Breslau N, Lipton RB, Stewart WF, Schultz LR, Welch KMA. Comorbidity of migraine and depression: investigating potential etiology and prognosis. Neurology 2003; 60: 1308-12.

22. Guidetti V, Galli F, Fabrizi PA, et al. Headache and psychiatric comorbidity: clinical aspects and outcome in an 8-year followup study. Cephalalgia 1998; 18: 455-62.

23. Karwautz A, Wöber C, Lang TA, et al. Psychosocial factors in children and adolescents with migraine and tension-type headache: a controlled study and review of the literature. Cephalalgia 1999; 19: 32-43.

24. Croft PR, Papageorgiou AC, Ferry S, Thomas E, Jayson MI, Silman AJ. Psychologic distress and low back pain. Evidence from a prospective study in the general population. Spine 1995; 20: 2731-37.

25. Baskin SM, Lipchik GL, Smitherman TA. Mood and anxiety disorders in chronic headache. Headache 2006; 46: 76-87.

26. Smitherman TA, Kolivas ED, Bailey JR. Panic disorder and migraine: comorbidity, mechanisms, and clinical implications. Headache 2013; 53: 23-45.

27. Lucchetti G, Peres MF, Lucchetti AL, Mercante JP, Guendler VZ, Zukerman E. Generalized anxiety disorder, subthreshold anxiety and anxiety symptoms in primary headache. Psychiatry Clin Neurosci 2013; 67: 41-49.

28. Ashina S, Serrano D, Lipton RB et al. Depression and risk of transformation of episodic to chronic migraine. J headache and pain 2012; 13: 615. 